Running head: MENTAL TOUGHNESS IN ADOLESCENT PERFORMERS

\title{
Adolescent Performers' Perspectives on Mental Toughness and its Development: The Utility of the Bioecological Model
}

John W. Mahoney ${ }^{1,3}$, Daniel F. Gucciardi ${ }^{2}$, Clifford J. Mallett ${ }^{1}$, Nikos Ntoumanis ${ }^{3}$

\author{
${ }^{1}$ The University of Queensland, School of Human Movement Studies \\ ${ }^{2}$ Curtin University, School of Physiotherapy and Exercise Science \\ ${ }^{3}$ Birmingham University, School of Sport, Exercise, and Rehabilitation Sciences
}

Author Note

Correspondence concerning this article should be addressed to John Mahoney, School of Human Movement Studies, The University of Queensland, St Lucia, Brisbane, QLD, Australia 4067. Telephone: +61 73365 6240. Fax: +61 73365 6877. Email: j.mahoney@psy.uq.edu.au

To appear in: The Sport Psychologist Accepted for publication: $19^{\text {th }}$ December 2013 
Running head: MENTAL TOUGHNESS IN ADOLESCENT PERFORMERS

\begin{abstract}
In light of the extant literature, the aim of the current study was to compare adolescents' perspectives on mental toughness and its development across performance contexts, and to explore if such perspectives align with Bronfenbrenner's (2001) bioecological model. Eighteen mentally toughness adolescents ( 9 boys, 9 girls, Mage $=15.6$ years) from three performance contexts (i.e., sport, academia, and music) participated in focus groups, 7 of which also participated in follow-up 1-1 interviews. Inductive analyses revealed that mental toughness was conceptualized by 9 personal characteristics and that, whilst similar across performance contexts, some difference between previous mental toughness conceptualization and the current study existed. Analysis also revealed that mental toughness development was predicated on significant others, supportive social processes, critical incidents, and curiosity. These findings resonated with the properties of the bioecological model. Future research into how bioecological factors combine to facilitate mental toughness development during critical stages of life was suggested.
\end{abstract}

Keywords: Performance contexts; human potential; positive youth development. 
Running head: MENTAL TOUGHNESS IN ADOLESCENT PERFORMERS

\section{Adolescent Performers' Perspectives on Mental Toughness and its Development: The Utility of the Bioecological Model}

The coniferous Redwood is the tallest tree species on earth. However, the likelihood of a Redwood seedling reaching its expected height is slim. In order to germinate, a single Redwood seedling not only needs to possess hardy qualities such as a strong outer cone, but also requires fertile soil, adequate sunlight and water, and to evade herbivorous diseases and predators. Despite being engineered to stand taller than all other tree species, few Redwood seedlings reach the soaring heights expected of them. The human journey is markedly similar to that of the Redwood in the sense that humans are also said to aspire to realize their full potentials and are vulnerable to challenges to their growth (Maslow, 1943). Like the Redwood, the qualities humans possess, the environments that surround them during critical and sensitive periods of growth, and the timing of events during their development play a significant role in determining the 'heights' they will reach in later life (e.g., Huurre, Eerola, Rahkonen, \& Aro, 2007; Johnson, Hicks, McGue, \& Iaconno, 2007).

Drawn from sport psychology literature, research on mental toughness offers a potentially informative standpoint from which to consider the processes that predict whether or not individuals will reach their full heights. A variety of mental toughness definitions and conceptualizations have been developed over the past decade, either inductively from key stakeholders' perspectives (Bull, Shambrook, James, \& Brooks, 2005; Gucciardi, Gordon, \& Dimmock, 2008, 2009; Jones, Hanton, \& Connaughton, 2007) or deductively by integrating anecdotal reports and applied work in sport psychology with established theory on hardiness from health psychology (Clough, Earle, \& Sewell, 2002) as well as innovatively drawing from neuropsychological perspectives (Hardy, Bell, \& Beattie, 2013). Common themes amongst the extant literature suggests that mental toughness can be defined as a collection of personal characteristics (i.e., forces, resources, and demands, discussed later) that allows 
Running head: MENTAL TOUGHNESS IN ADOLESCENT PERFORMERS

individuals to regularly perform to or around the best of their abilities regardless of circumstances faced (Clough et al., 2002; Coulter, Mallett, \& Gucciardi, 2010; Hardy et al., 2013; Jones et al., 2007). Researchers have generally agreed on conceptualizations of mental toughness, despite superficial, nomenclature differences. Elucidating this point, Connaughton, Thelwell, and Hanton (2011), in their recent synthesis of previous mental toughness conceptualizations from sport settings, proposed that mental toughness was comprised of nine personal characteristics: belief, coping, focus, motivation, control, sporting intelligence, resilient attitude, personal values, and physical toughness. Connaughton et al.'s (2011) synthesis, whilst drawn from the extant literature from sport settings alone, offers a meaningful starting point from which to understand mental toughness beyond the homogeneous samples.

Previous research has provided an important foundation upon which to clarify our understanding of mental toughness, yet these conceptualizations are based primary on the viewpoints of adult athletes. As such, it is possible that these conceptualizations of mental toughness might not generalize to individuals from other developmental periods of life (i.e., adolescence). For example, mental toughness might be conceptualized differently by adolescents (approximately 11-18 years of age; e.g., Dubow, Huesmann, Boxer, Pulkkinen, \& Kokko, 2006; Ericsson, Krampe, \& Tesch-Römer, 1993; Johnson et al., 2007) because of the different demands (e.g., time demands) and personal pursuits (e.g., the search for social identity in adolescents) characteristic of this life stage. Research on resilience - a concept related to, but distinguishable from mental toughness (see, Gucciardi, Gordon, \& Dimmock, 2009) - highlights that the personal characteristics that facilitate human functioning during times of adversity can vary across different life stages (Ryff, Singer, Love, \& Essex, 1998). Such knowledge foregrounds the contention that past conceptualizations of mental toughness are not necessarily generalizable to adolescents. Adolescence is an ideal development phase 
Running head: MENTAL TOUGHNESS IN ADOLESCENT PERFORMERS

in which to study mental toughness because it is a period characterized by more maturational, educational, and interpersonal challenges and changes than any other stage of life (Montemayor, Adams, \& Gullotta, 1990). The ability to not only successfully negotiate these challenges and changes, but to also thrive during them is consistent with the aforementioned definition of mental toughness.

Additionally, with research isolated to sport settings alone, it is difficult to generalize previous understandings of mental toughness to other performance contexts (e.g., academia, music). Although some scholars have speculated about the generalizability of mental toughness to other performance contexts (Colbert, Scott, Dale, \& Brennan, 2012), researchers need to empirically explore the merit of such contentions. According to Lazarus (2000), all performance contexts are underscored by similar motivational (e.g., to score a top grade in a school exam), attentional (e.g., focusing on finger placement when playing the violin), and strategic (e.g., exposing opponent's weaknesses in invasion sports) elements that place cognitive demands on individuals. As such, it is possible that there are a group of personal characteristics that, in combination, allow individuals, regardless of performance context, to regularly perform to their abilities regardless of circumstances faced. However, it is difficult to be certain about such speculations without appropriate supporting evidence.

Considering that mental toughness could present variations between different life stages, researchers should consider how this construct is acquired from a developmental perspective. Gould and colleagues (Gould, Dieffenbach, \& Moffett, 2002; Gould, Hodge, Peterson, \& Petlichkoff, 1987), have suggested that mental toughness is one of the central psychological traits key to the sustainment and attainment of performance standards. As such, an understanding of how to develop mental toughness is important for the fulfillment of individuals' performance capabilities. Drawing from broader psychological enquiry (Gottesman \& Hanson, 2005), human development is often recognized as being predicated on 
Running head: MENTAL TOUGHNESS IN ADOLESCENT PERFORMERS

by a combination of genetic predispositions (i.e., nature) and lived experiences (i.e., nurture). In line with such knowledge, some researchers have contested that genetic factors determine differences in individuals' levels of mental toughness. However, the body of research that has theorized a genetic basis for mental toughness (Crust, 2007; Hardy et al., 2013; Mallett \& Coulter, 2011) is small and, in the case of quantitative evidence (Horsburgh, Schermer, Veselka, \& Vernon, 2009), limited by the use of measures with unsubstantiated psychometric support (Gucciardi, Hanton, \& Mallett, 2012). More typically researchers (e.g., Connaughton, Hanton, \& Jones, 2010; Weinberg, Butt, \& Culp, 2011) have contested that the personal characteristics that comprise mental toughness are developed through lived experiences. Researchers have identified more than 20 factors as contributing to the development of mental toughness (Connaughton et al., 2010; Connaughton, Wadey, Hanton, \& Jones, 2008; Gucciardi, Gordon, Dimmock, \& Mallett, 2009; Thelwell, Such, Weston, Such, \& Greenlees, 2010; Weinberg et al., 2011). Although a meaningful starting point, many of these factors are conceptually equivalent (e.g., mastery, skill mastery, and achievement of performance gains) and prompt the need for a clearer understanding of the factors that contribute to mental toughness development.

One approach for better understanding the interplay between nature and nurture, as well as clarifying the factors that contribute to the development of mental toughness is to draw on established theoretical models of human development. Although some researchers have proposed sport-specific models of mental toughness development (e.g., Bull et al., 2005), the generalizability of such models to wider populations has yet to be determined. As an alternative, and to ensure the generalizability of a model of mental toughness development, we consider literature from broader fields of psychological enquiry. Brofenbrenner's (2001) bioecological model is one such theory that has the potential to provide an integrative framework for previous research, as well as new findings pertaining to 
Running head: MENTAL TOUGHNESS IN ADOLESCENT PERFORMERS

mental toughness development (also see, Krebs, 2009a). This model was selected over other general models of development at it represents a broad, robust theoretical foundation upon which to build an understanding of mental toughness development, as well as taking into account a number of key principles present in other developmental theories (see, Bronfenbrenner \& Morris, 2006). In accordance with the bioecological model, development is defined as "the phenomenon of continuity and change in the biopsychological characteristics of human beings" (Bronfenbrenner \& Morris, 2006, p. 793). Along with this definition, four properties serve as the foundations for elucidating how development occurs: proximal processes, personal characteristics, ecological contexts, and time.

Proximal processes are described as the primary and direct producers of development and are posited within the bioecological model as the most substantive and theoretically significant property that drives development (Bronfenbrenner, 2005; Krebs, 2009b). Such processes refer to the progressively more complex, reciprocal interactions that occur between developing individuals and their environments. In other words, enduring developmental changes, of both a functional and dysfunctional nature, occur in individuals following repeated encounters with experiences that challenge and continue to challenge learning, understanding, and ability. Examples of proximal processes from past mental toughness research include competitive and vicarious experiences, competitive and sibling rivalries, and challenging and demanding training environments (Butt, Weinberg, \& Culp, 2010; Connaughton et al., 2010; Connaughton et al., 2008; Gucciardi, Gordon, Dimmock, et al., 2009; Thelwell et al., 2010).

Personal characteristics, as described in the bioecological model, foregrounds the agentic role of individuals in their development. Bronfenbrenner and Morris (2006) asserted that human development is determined, in part, by three process-relevant personal characteristics: forces, resources, and demands. Forces refer to the temperaments and 
Running head: MENTAL TOUGHNESS IN ADOLESCENT PERFORMERS

motivations of individuals that promote both the degree and endurance of emotional and behavioural control. In line with the notion of personal forces, Connaughton and colleagues (Connaughton et al., 2010; Connaughton et al., 2008) reported that mental toughness was subject to development through athletes' heightened competitive drive and their insatiable desire and internalized motives to succeed. Resources pertain to the past experiences, skills, and intelligences of developing individuals. The notion of personal resources has also been highlighted in previous research exploring mental toughness development. In particular, researchers have highlighted that past successes, the ability to reflect on experiences, and knowledge of a wide repertoire of skills and strategies contribute to the development of mental toughness (Connaughton et al., 2010). Finally, demands refer to the stimuli and information immediately available to others upon encountering developing individuals (e.g., gender, age, physical strength) and are presumed to influence development through social expectations. An example of a demand characteristic from past mental toughness research includes physical toughness. Coaches may view athletes with high degrees of physical toughness as capable of enduring advanced challenges and more demanding activities and, as such, expose them to greater opportunities that would accelerate their development. In line with the bioecological model, personal characteristics "function both as an indirect producer and as a product of development" (Bronfenbrenner \& Morris, 2006, p.798). In line with this contention, we not only consider the agentic role of individuals in their development, but also how notions of forces, resources, and demands can help categories and explain mental toughness conceptualizations (hence the explicit use of the term, personal characteristics, in the definition of mental toughness presented above).

The third property detailed in the bioecological model as influencing development is ecological contexts. Ecological contexts refer to the physical and social environments that surround developing individuals and are theorized to constitute four principal systems: the 
Running head: MENTAL TOUGHNESS IN ADOLESCENT PERFORMERS

microsystem, mesosystem, exosystem, and macrosystem. The microsystem concerns the direct influence of others' and environments on the development of individuals (e.g, how parents rear their children). Mesosystem concern the affect of the relationship between two or more microsystems (e.g., the relationship between family and school) on the development of individuals. Exosystems detail how the relationship between microsystems and individuals or groups not directly involved in an individuals' life affect development (e.g., how the demands of work influences parents' time spent with their children). Finally, macrosystems refer to the features of the community or culture to which a developing individual belongs (e.g., community and cultural beliefs and practices surrounding social justice). The variety of these contexts illustrates that development is predicated on by individuals' direct interactions with individuals within their immediate environments, but also the activities occurring in broader contexts that do not necessarily involve them. Thelwell et al. (2010), in a study with elite gymnasts, identified that mental toughness development was not only predicated by athletes' interactions with individuals from their immediate social environments (i.e., microsystems), but also interactions between ecological contexts such as family and club environments (i.e., mesosystems), as well as societal expectations (i.e., macrosystems).

Finally, the bioecological model includes time as a property that affects development. Historical (e.g., past events, such as compulsory education, that have altered trends in academic curricular) and personal (e.g., age of entry to sport, age of first music lesson) events are two ways in which time is argued to influence development. In other words, it is not only the occurrence of events that influence individuals' development, but also when they occur. Similar notions have been purported in mental toughness literature. For instance, Connaughton and colleagues' $(2010 ; 2008)$ illustrated that the factors that contribute to mental toughness development varied as athletes specialized in their chosen sport. Taken together, the properties that underscore the bioecological model appear to have the potential 
Running head: MENTAL TOUGHNESS IN ADOLESCENT PERFORMERS

to provide an integrative framework for previous research, as well as new findings pertaining to mental toughness development.

In light of the information detailed above, the first aim of the current study was to investigate adolescents' perspectives on mental toughness and its development across different performance contexts. Investigating adolescent performers' perspectives provides an opportunity to alleviate methodological concerns of previous research (i.e., retrospective recall bias; Connaughton et al., 2010; Connaughton et al., 2008), as well as contribute substantive insights into the personal characteristics considered most important during a critical developmental stage. The inclusion of multiple performance contexts in the current study also advances the literature by extending the focus of mental toughness research beyond sport settings alone. It is for these two aforementioned reasons that we undertook exploratory research as opposed to reviewing the extant literature. We believe our attempts to address the limitations of previous research and advance understanding beyond sport settings alone will garner new evidence about mental toughness and its development and, as such, serve as a meaningful and contemporary foundation upon which to address the second aim of the study. The second aim of the current study was to investigate the utility of the bioecological model as an integrative framework useful for understanding mental toughness and its development in adolescent performers.

\section{Method}

\section{Participants}

Two independent single-sex high schools (one all boys; one all girls) were contacted to participate in the study. Both schools were purposely selected based on their publicly recognized high performances across sport (i.e., both schools consistently placed within the top three in regional inter-school sport competitions), academia (i.e., both schools were categorized as 'substantially above' the national average according to the Australian 
Running head: MENTAL TOUGHNESS IN ADOLESCENT PERFORMERS

Curriculum Assessment and Reporting Authority, 2012) and music (i.e., both schools consistently placed within the top three in regional and national inter-school recitals). This approach to recruitment is consistent with qualitative methodologies (Lincoln \& Guba, 1985; Patton, 2002) and previous mental toughness research (e.g., Jones, Hanton, \& Connaughton, 2002).

Because of their knowledge of the student body, faculty Deans (i.e., Dean of Sport, Dean of Music, Dean of Studies) at each school were asked to identify pupils from sport, academia, and music to participate in the study. The following description was provided to these staff to guide their selections: "Individuals who regularly perform to or around the best of their abilities regardless of circumstances faced - positive, negative, or otherwise." This description, consistent with and adapted from mental toughness definitions (Coulter et al., 2010; Gucciardi et al., 2008; Jones et al., 2007), was selected because it avoided the use of wordy and complex academic jargon and directed school staff past norm-referenced high performers toward self-referenced high performers (i.e., those who perform to or around the best of their abilities). It was deemed important to qualify mental toughness as a selfreferenced concept to garner information from individuals who were not categorized solely as 'elite' performers. This qualification is supported by research findings in sport that highlight that 'elitism' is not necessarily indicative of positive or sustainable growth (Schaal et al., 2011) and also addresses a major criticism of past mental toughness research (Andersen, 2011).

Eighteen adolescents ( 9 boys, 9 girls, $M_{\text {age }}=15.6$ years, age range: $13-17$ ) were recruited to participate in the study. Three male and three female adolescents represented each context (e.g., 3 male and 3 female musicians). One male participant represented both sport and academia. Participants who represented sporting domains competed in the highest or second highest level of competition for their age group in inter-school competitions (e.g., 
Running head: MENTAL TOUGHNESS IN ADOLESCENT PERFORMERS

$1^{\text {st }}$ VIII rowing; under 14 'B' basketball squad). Similarly, participants who represented music performed in either the highest or second highest school ensembles for their school in inter-school and national recitals. Those who represented academia achieved within the top $20 \%$ of their cohort on state-wide examinations. The standings and performances of participants portrayed them as a high performing group, but not necessarily elite.

\section{Procedure}

Institutional ethical approval and participant and parental consent was obtained prior to the commencement of data collection. The study consisted of two semi-structured focus group interviews with equal numbers of participants separated by gender (e.g., 9 female adolescents: 3 musicians, 3 students, and 3 athletes). Focus groups were selected for two reasons (Vaughn, Schumm, \& Sinagub, 1996). First, focus groups provide a non-hostile environment where individuals often feel encouraged to voice their own opinions, especially in the presence of unfamiliar social agents (e.g., the focus group coordinator). Creating a nonhostile environment was important considering the participants' ages, as adolescents are more likely to conform with others if they feel socially uncomfortable (Costanzo \& Shaw, 1966). As such, adolescents participated in focus groups with peers from the same school, as it was believed that this would likely create a safe and comfortable social environment. Second, focus groups were selected as they often encourage deeper thought as individuals are presented with ideas that they may disagree with (and therefore have to argue against) or that they may not have contemplated previously (and therefore have to integrate with their own beliefs). For this reason each performance setting was equally represented in an attempt to generate discussions both between and within performance groups.

To facilitate focus group discussions, a brief worksheet, developed in line with performance profiling procedures (Gucciardi \& Gordon, 2009), was used initially to elicit the personal characteristics that participants believed allowed them to regularly perform to or 
Running head: MENTAL TOUGHNESS IN ADOLESCENT PERFORMERS

around the best of their abilities regardless of circumstances faced. These characteristics were categorized under the heading "emergent characteristics." In line with performance profiling procedures and to form a robust understanding of adolescents' perspectives, participants were then asked to consider the opposite pole of these emergent characteristics. These personal characteristics were categorized under the heading "opposite characteristics". Subsequent to this task, participants were requested to provide definitions of both the emergent and opposite personal characteristics they recorded. As a guide, and before attempting the worksheet, participants were presented with a worked example of an unrelated topic (i.e., the qualities of a 'good friend'). Following the completion of the worksheet, the focus group coordinator led a discussion to elucidate participants' perspectives and opinions about the personal characteristics and definitions they had recorded. An example question included, "how does [personal characteristics] help you in your performances, if at all?"

The worksheet activity was followed by group discussions about what factors contributed to the development of the identified personal characteristics. Participants were first asked to generate a list of factors that they believed contributed to the development of the personal characteristics they reported. As a group, participants were then probed about how such factors contributed to the development of specific personal characteristics listed during the worksheet activity. An example question included, "how, if at all, does [factor] contribute to the development of the list of personal characteristics discussed before?"

Approximately 2 weeks after the focus groups 7 adolescents ( 3 male: 1 sport, 1 music, 1 sport and academia; 4 female: 2 academia, 2 music) were invited to participate in follow-up 1-1 interviews. The intention of these 1-1 interviews was not to increase the breadth of information gathered during the focus groups, but rather to garner deeper perspectives about mental toughness conceptualizations and development. To service this aim, participants were selected based on their abilities to articulate and think critically about their points of view (as 
Running head: MENTAL TOUGHNESS IN ADOLESCENT PERFORMERS

deemed by the research team following inspection of the focus group transcripts and in consultation with the faculty Deans at each school). The purposeful selection of informationrich cases for the purposes of enhancing the depth of knowledge of a research field is supported in commentaries about best practices in qualitative research design (Patton, 2002). The established relationships with participants following the focus groups facilitated 1-1 interviews appeared to encourage participants to think critically about their responses, further servicing the aforementioned aim.

Prior to the commencement of the follow-up interviews, the lead author and a thirdparty researcher - both trained in qualitative methodologies - devised a set of questions pertaining to the development of the personal characteristics believed central to performing to the best of one's abilities based on transcripts from the focus groups. These questions were then presented, discussed, and altered as deemed necessary by the second and third authors. An example question was, "How, if at all, did your parents contribute to the development of your self-belief?". This mixed approach reflects the contentions of Yardley and Bishop (2007) who argued that analysing composite procedures enhances the validity of qualitative data.

Attention was paid during the focus groups and 1-1 interviews to ensuring responses were not influenced by biased or leading questions. Protocols drawn from personal construct psychology (cf. Gucciardi \& Gordon, 2009) were followed to uphold the integrity of data collection procedures and provide participants with opportunities to respond in line with their own insights. For example, the initial worksheet activity was completed with minimal, if any, guidance from the focus group coordinator.

\section{Data Analysis}

The focus groups and individual interviews were transcribed verbatim (55 pages of single-lined text) and coded using a four-stage interpretative phenomenological procedure 
Running head: MENTAL TOUGHNESS IN ADOLESCENT PERFORMERS

(Storey, 2007). This procedure was employed because it allowed participants' responses pertaining to personal characteristics to be analyzed in an inductive manner. Stage one of the procedure involved the reading and re-reading of transcripts (and, in this case, worksheet responses as well), and the journaling of notes relevant to the text. The second stage involved returning to these notes to identify themes that integrated participants' phenomenologies (i.e., their subjective understandings). Single words or short phrases that summarized and conveyed meaning were written alongside the notes from stage one. The third stage involved the linking of themes and identification of thematic clusters. The analysts (i.e., the first and second author, as well as a third-party researcher) categorized words and phrases from the previous stage together based on apparent similarities. In the fourth stage, the actions from the previous three tasks were compiled and presented in summary tables (see Table 1 and 2). Following this four-stage procedure, factors thought to contribute to mental toughness development were analyzed alongside the four properties of the bioecological model (i.e., proximal processes, person factors, ecological contexts, and time).

\section{Trustworthiness}

Three traditional techniques were employed to ensure trustworthiness of the data (Lincoln \& Guba, 1985). First, two researchers - the first author and a third-party researcher (unaware of the aims of the study) - both experienced with qualitative research methods independently analyzed the data. This initial round of transcript assessments revealed $80 \%$ agreement between the two analysts. Subsequently, the second author made comments about discrepancies and, together, the three analysts discussed their interpretations of the data until consensus was reached. Finally, a detailed overview of the results was presented to all participants following analysis. Participants were asked to reflect on and verify the accuracy of the analysts' interpretations. Participants voiced no disagreements during this presentation.

\section{Results and Discussion}


Running head: MENTAL TOUGHNESS IN ADOLESCENT PERFORMERS

We begin this section with an overview of the personal characteristics identified by participants across performance contexts, employing notions drawn from the bioecological model to help categorise each. Subsequently, the factors that emerged from the interviews as contributors to the development of these personal characteristics are then discussed. These findings are then interpreted in light of the bioecological model. Finally, general conclusions about the findings of the current study are discussed, especially with regards to the unique contributions of the research and proposed directions for future research.

\section{Personal Characteristics}

Nine personal characteristics emerged from the data collected during the worksheet activity. They included four personal forces - persistence, drive, high self-expectations, and support seeking - and five personal resources - forethought, social intelligence, heightened awareness, self-belief, and optimistic thinking (see Table 1 for descriptions, opposite poles, and representative quotes of each). In line with the bioecological model, personal forces were characterized by temperaments and motivations of individuals that promote both the degree and endurance of emotional and behavioural control. Further, personal resources were characterized by the past experiences, skills, and intelligences of developing individuals. No personal demands were reported by participants, which is contrary to previous mental toughness research. A possible speculative explanation for this omission may be that adolescents are naïve about how characteristics such as their age and gender influence the actions of those around them and, as a consequence, affect their development.

Despite the omission of personal demands, the nine personal characteristics reported were otherwise consistent with previous research that has examined mental toughness in sport. Self-belief (cf. belief), drive (cf. motivation), heightened awareness (cf. sport intelligence), optimistic thinking (cf. resilient attitude) and high self-expectations (cf. personal values) are mirrored in those personal characteristics reported in Connaughton et 
Running head: MENTAL TOUGHNESS IN ADOLESCENT PERFORMERS

al.'s (2011) synthesis of the mental toughness literature. Persistence shared conceptual territory with how Connaughton et al. (2011) described coping, but extended beyond simply overcoming obstacles to also include sustained efforts during non-challenging tasks. Control and physical toughness did not emerge in the current study despite evidence for these two personal characteristics in previous conceptualizations of mental toughness. The former may not have emerged as the ability to control one's experiences may be indicative of advanced development and more likely to emerge in more mature, older samples (Chubb, Fertman, \& Ross, 1997). Physical toughness may not have emerged for two reasons. First, physical attributes are unlikely to be deemed important to performances in non-athletic pursuits (e.g., music, academia). Second, even within athletic pursuits, if physical attributes are everchanging, as they are during adolescence, performers may be more inclined to place greater value on more stable personal characteristics, especially those under their control. Additionally, the notion of a disciplined focus, which has appeared in numerous past conceptualization of mental toughness and which is theorized as central to performance contexts (Lazarus, 2000), was only discussed by participants from sport and music settings. For this reason, it was not included in the final conceptualization. It is possible that a disciplined focus is central to performing to the best of one's abilities, but only in settings where external distractions (e.g., audience noise, the conductor, opponents) are salient during performance, as in sport and music settings.

Forethought, social intelligence, and support seeking were unique personal characteristics that emerged in the current study. The emergence of forethought may be due to the perceived increased demands on time characteristic of adolescence (e.g., de Anda et al., 2000; Hilbrecht, Zuzanek, \& Mannell, 2008). Further, the emergence of social intelligence and support seeking in the current study may be explained by the increased importance placed on social identity and social roles during adolescence (Keating, 2004; Montemayor et 
Running head: MENTAL TOUGHNESS IN ADOLESCENT PERFORMERS

al., 1990; Susman \& Rogol, 2004). Adult samples from previous mental toughness research may not have identified these personal characteristics because they had already undergone and resolved such experiences and, therefore, did not view them as salient to facilitating their performances. Taken together, our findings suggest that a core group of personal characteristics contribute to the attainment and sustainment of performance standards and that such personal characteristics are consistent across performance contexts and diverge from those thought important by adult athlete samples.

\section{Developing Personal Characteristics}

Four higher order themes - significant others, supportive social processes, critical incidents, and curiosity - emerged as the factors believed to contribute to the development of the aforementioned personal characteristics. Supportive social processes were further characterized by four lower order themes (autonomy, encouragement, challenge, and role modeling), whereas critical incidents encompassed three lower order themes (early successes, varied experiences, and failures/setbacks). Significant others and curiosity were not categorized by any lower themes. Table 2 includes definitions and representative quotes of each theme. As with the participants' perspective of the key personal characteristics, considerable consistencies were observed between the adolescents in terms of the factors they believed contributed to mental toughness development. These findings provide preliminary support for the contention that the development of personal characteristics that comprise mental toughness appear to share consistencies across performance contexts. To elucidate these contentions further, the findings of the current study are interpreted in light of the tenets of the bioecological model.

\section{Integrating Participants' Perspectives with the Bioecological Model}

The four tenets of the bioecological model - proximal processes, personal characteristics, ecological contexts, and time - were visible in the participants' discourse. 
Running head: MENTAL TOUGHNESS IN ADOLESCENT PERFORMERS

Both supportive social processes and critical incidents resonated with Bronfenbrenner's (2001) notion of proximal processes. Specifically, our findings revealed that repeated exposure to autonomy, encouragement, challenges, and role modelling was key to mental toughness development in adolescent performers. As one male musician noted about his teacher, "He's always [italics added] giving me different forms for competitions and things I wouldn't normally do". Similarly, participants indicated that, rather than isolated incidents, repeated encounters with critical incidents (i.e., early successes, varied experiences, and failures/setbacks) contributed to the development of mental toughness. The critical incidents reported in the current study were also consistent with the bioecological model and emphasise how proximal processes contribute to mental toughness development. Critical incidents contributed to mental toughness development through the continual challenging of individuals' learning, understandings, and abilities. Illustrating this point, one male athlete stated, "I'd rather work off something I did wrong last week thinking how I'm going to do it better next week." As such, a single event was not viewed as contributing to mental toughness development, but rather ongoing, regular exposure to positive and challenging environments. In line with the bioecological model, as proximal processes are the principle property that drives development, it is unsurprising that participants' responses were dominated by themes that reflected this category.

Consistent with personal characteristics, in particular personal forces, as details in the bioecological model, the emergence of curiosity illustrated the agentic role individuals play in their development of the personal characteristics that conceptualize mental toughness. One male musician, for example, described himself as a "black hole" that "takes in all those qualities that are good". In consideration of the bioecological model, person factors are argued to influence the mechanisms that drive development (i.e., proximal processes). In other words, curiosity may influence how supportive social processes and critical incidents 
Running head: MENTAL TOUGHNESS IN ADOLESCENT PERFORMERS

contribute to individuals' development. Illustrating this person-environment interaction, curious individuals who encounter failures may be more likely to approach such experiences as opportunities to learn compared to close-minded individuals. Such contentions are further supported by theory and research on curiosity from broader psychology domains (Kashdan \& Steger, 2007). It is important to note that curiosity was viewed as a factor that influenced the development of, but that did not conceptualize mental toughness. The notion that personal factors are both producers and products of development is consistent with the bioecological model (Bronfenbrenner \& Morris, 2006).

The identification of significant others and the description of how supportive social processes contributed to mental toughness development was consistent with Bronfenbrenner's detailing of ecological contexts, or the physical and social environments that surround developing individuals. Participants highlighted that individuals such as parents, siblings, teachers, coaches, and peers (i.e., significant others) were instrumental in the development of the aforementioned personal characteristics through the types of support they demonstrated (i.e., supportive social processes). Bronfenbrenner, in his bioecological model, stressed that the immediate environments that surround individuals (i.e., microsystems) have a profound effect on development. There were also suggestions from the participants' discourses to support the role of mesosystems and exosystems in the development of mental toughness. For example, role modelling illustrated how individuals, groups, and contexts, could interact, independently of the developing individual, to facilitate mental toughness development. For example, one participant described how his siblings role modelled persistent behaviors in his chosen sport, "I saw my brothers rowing in the first VIII and pushing themselves so hard, that inspired me" (i.e., mesosystems)", but also how his father role modelled similar actions in his work, "dad just manages to keep pushing himself so hard through his work and I've always found that inspiring" (i.e., exosystems). The results 
Running head: MENTAL TOUGHNESS IN ADOLESCENT PERFORMERS

of the current study support such tenets of the bioecological model, emphasizing that individuals' immediate and surrounding environments facilitate the development of mental toughness. However, macrosystems did not emerge and may be explained by participants' limited awareness of the processes that do not closely include or affect them, but that may still contribute to their development.

Time, or the onset of events, in particular critical incidents, was viewed by participants as pertinent to mental toughness development. The reference to early successes indicated that not only were positive experiences viewed as central to the development of mental toughness, but just as central was the timing of such experiences. Further, there appeared a critical phase by which failure and/or setbacks needed to be experienced to develop mental toughness. As examples, one male athlete stated, "more recently, I think the failures that I have had have motivate me more than my successes", whilst one female musician commented, “if you win everything, then when you lose you won't know how to learn from your mistakes, you won't know how you have to improve". This finding, in particular those pertaining to failures and setbacks, comes as a surprise, as intuitively and empirically (e.g., Boekaerts, 1996; Folkman \& Lazarus, 1985) negative experiences are more likely to be associated with developmental disruptions. However, it is possible that not only the experience, nor timing, but also personal factors such as a curious disposition, determine the likelihood that failures/setbacks will contribute generatively to individuals' development (Krebs, 2009a). Based on participants' perspectives, if individuals are exposed to failure/setbacks - and/or successes for that matter - at inopportune times then mental toughness development is likely to be impeded. With the aforementioned in mind, time is an important addition to person-environment interactions that facilitate mental toughness development. Participants made no reference to historical time, but, as before, this may be 
Running head: MENTAL TOUGHNESS IN ADOLESCENT PERFORMERS

due to adolescents' limited awareness of the events occurring outside those in which they are immediately involved.

Based on the aforementioned discussion, the bioecological model appears to have utility for understanding mental toughness and its development. Importantly, in line with participants' perspectives, the model illustrates the process-person-context-time (PPCT, Bronfenbrenner \& Morris, 2006) interactions that contributes to mental toughness development. Previous research, whilst acknowledging these ideas broadly, has not identified the manner in which PPCT properties interact to facilitate mental toughness development. Support for PPCT interactions provides unique insight into mental toughness development and highlights a substantive contribution of the current study. Despite this contribution, no evidence emerged to support the role indirect ecological contexts or historical time plays in the development of mental toughness. Whilst, as suggested, this might be due to the limited insights of participants, it may also reflect inconsistencies between mental toughness development and tenets of the bioecological model. Further research is required to resolve this uncertainty.

\section{General Conclusion}

This study is among the first to examine adolescents' perspectives on mental toughness and its development in three performance contexts, thereby providing an insight into the generalizability of previous work that has been conducted primarily with elite, adult athletes. Unique to the current study was evidence for three personal characteristics not previously reported in mental toughness research with adult athletes (i.e., forethought, social intelligence, and support seeking). The emergence of these personal characteristics in the current study suggested that mental toughness is conceptualized differently depending on developmental brackets to which individuals belong. Specifically, compared to adults, adolescents appear to require a group of personal characteristics that more closely reflect the 
Running head: MENTAL TOUGHNESS IN ADOLESCENT PERFORMERS

developmental milestones they are pursuing (e.g., social and self-identity) in order to regularly perform to or around the best of their abilities regardless of circumstances faced.

Most notably, however, the factors reported as contributing to the development of mental toughness were largely consistent with established theory. The utility of the bioecological model (Bronfenbrenner, 2001) for interpreting participants' perspectives paves the way for a deeper understanding of and investigation into mental toughness development. The congruence between participants' perspectives and the tenets of the model provide preliminary support for the utility of a PPCT interactional approach in future research, as opposed to biasing environmental factors alone. Our findings reveal that, for example, whilst individuals might be exposed to meaningful environmental factors (e.g., task challenges), the influence of such factors on mental toughness development may be in vein unless coupled with adequate support from significant others, a curious disposition, and timed appropriately. Additionally, due to the lack of evidence for particular aspects of the model (i.e., certain ecological contexts and historical time), future research could explore how environments and events that indirectly affect adolescents influence mental toughness development, if at all.

The current study extended upon past research by considering mental toughness and its development in populations beyond those previously considered. Despite this contribution, future research is needed to overcome the limitations of the current study. Specifically, the current study examined adolescence as a broad developmental group. However, some scholars have theorized that development, particularly in performance contexts such as sport, can be separated into smaller developmental brackets (Bloom, 1985). As such, future research could explore mental toughness development in both younger and older adolescents. Another limitation of the current study was the consideration of the perspectives of adolescents from higher socio-economic backgrounds. In light of the emphasis the bioecological model places on ecological contexts, researchers should compare different 
Running head: MENTAL TOUGHNESS IN ADOLESCENT PERFORMERS

socio-economic groups to ascertain how the exposure to different environments might contribute to mental toughness development. Enquiry along such lines might also overcome an omission of the current study by also exploring the factors that disrupt or thwart mental toughness development. Such omissions could also be addressed by leveraging off past mental toughness research (Gucciardi, Gordon, Dimmock, et al., 2009) and sampling individuals involved in the development process (e.g., coaches, parents, teachers). Further still, the inclusion of significant others in future research could also be used as a means of stabilizing the recruitment of performers, especially considering our argument that mental toughness should be considered a self-referenced, as opposed to an other- or task-referenced construct. A final limitation of the current research was the use of cross-sectional data collection. The use of longitudinal qualitative approaches would serve to illustrate individuals' changing experiences and life courses, and would be a fruitful addition to future research (McLeod, 2009). By leveraging off the findings and addressing the limitations of the current study, researchers and practitioners will likely be better placed to support adolescents in their performance pursuits and, potentially, initiate positive trajectories to adult performance. 
Running head: MENTAL TOUGHNESS IN ADOLESCENT PERFORMERS

\section{Reference}

Andersen, M. B. (2011). Who's mental, who's tough and who's both? Mutton constructs dressed up as lamb. In D. F. Gucciardi \& S. Gordon (Eds.), Mental toughness in sport: Developments in theory and research (pp. 69-88). Abingdon, Oxon: Routledge.

Authority, A. C. A. a. R. (2012). National Assessment Program. (22nd August). Retrieved from http://www.nap.edu.au/

Bloom, B. (1985). Developing talent in young people. New York: Ballantine.

Boekaerts, M. (1996). Coping with stress in childhood and adolescence. In M. Zeidner \& N. S. Engler (Eds.), Handbook of coping: Theory, research, application. (pp. 452-484). Oxford, England: Wiley.

Bronfenbrenner, U. (2001). The bioecological theory of human development. In N. J. Smelser \& P. B. Baltes (Eds.), International encyclopedia of the social and behavioral sciences (Vol. 10, pp. 6963-6970). New York: Elsevier.

Bronfenbrenner, U. (Ed.). (2005). Making human beings human: Bioecological perspectives on human development. Thousand Oaks: CA: Sage.

Bronfenbrenner, U., \& Morris, P. A. (2006). The bioecological model of human development. In R. M. Lerner (Ed.), Handbook of child development: Theoretical models of human development (6th ed., Vol. 1, pp. 793-828). Hoboken, NJ: Wiley.

Bull, S. J., Shambrook, C. J., James, W., \& Brooks, J., E. (2005). Towards an understanding of mental toughness in elite English cricketers. Journal of Applied Sport Psychology, 17, 209-227. doi: 10.1080/10413200591010085

Butt, J., Weinberg, R., \& Culp, B. (2010). Exploring mental toughness in NCAA athletes. Journal of Intercollegiate Sport, 3, 316-332. 
Running head: MENTAL TOUGHNESS IN ADOLESCENT PERFORMERS

Chubb, N. H., Fertman, C. I., \& Ross, J. L. (1997). Adolescent self-esteem and locus of control: A longitudinal study of gender and age differences. Adolescence, 32, 113129.

Clough, P., Earle, K., \& Sewell, D. (2002). Mental toughness: The concept and its measurement. In I. Cockeril (Ed.), Solutions in sport psychology (pp. 32-45). London: Thomson.

Colbert, S. D., Scott, J., Dale, T., \& Brennan, P. A. (2012). Performing to a world class standard under pressure: Can we learn lessons from the Olympians? British Journal of Oral and Maxillofacial Surgery, 50, 291-297. doi: 10.1016/j.bjoms.2012.04.263

Connaughton, D., Hanton, S., \& Jones, G. (2010). The development and maintenance of mental toughness in the world's best performers. The Sport Psychologist, 24, 168-193.

Connaughton, D., Thelwell, R. C., \& Hanton, S. (2011). Mental toughness development: Issues, practical implications and future directions. In D. F. Gucciardi \& S. Gordon (Eds.), Mental toughness in sport: Developments in theory and research (pp. 135162). Abingdon, Oxon: Routledge.

Connaughton, D., Wadey, R., Hanton, S., \& Jones, G. (2008). The development and maintenance of mental toughness: Perceptions of elite performers. Journal of Sport Sciences, 26, 83-95. doi: 10.1080/02640410701310958

Costanzo, P. R., \& Shaw, M. E. (1966). Conformity as a function of age level. Child Development, 37, 967-975.

Coulter, T. J., Mallett, C. J., \& Gucciardi, D. F. (2010). Understanding mental toughness in Australian soccer: Perceptions of players, parents, and coaches. Journal of Sport Sciences, 28, 699-716. doi: 10.1080/02640411003734085

Crust, L. (2007). Mental toughness in sport: A review. International Journal of Sport and Exercise Psychology, 5, 270-290. 
Running head: MENTAL TOUGHNESS IN ADOLESCENT PERFORMERS

de Anda, D., Baroni, S., Boskin, L., Buchwald, L., Morgan, J., Ow, J., . . Weiss, R. (2000). Stress, stressors and coping among high school students. Children and Youth Services Review, 22, 441-463. doi: 10.1016/S0190-7409(00)00096-7

Dubow, E. F., Huesmann, L. R., Boxer, P., Pulkkinen, L., \& Kokko, K. (2006). Middle childhood and adolescent contextual and personal predictors of adult educational and occupational outcomes: A mediational model in two countries. Developmental Psychology, 42, 937-949. doi: 10.1037/0012-1649.42.5.937

Ericsson, K. A., Krampe, R. T., \& Tesch-Römer, C. (1993). The role of deliberate practice in the acquisition of expert performance. Psychological Review, 100, 363-406. doi: 10.1037//0033-295X.100.3.363

Folkman, S., \& Lazarus, R. S. (1985). If it changes it must be a process: A study of emotion and coping during three stages of a college examination. Journal of Personality and Social Psychology, 48, 150-170.

Gottesman, I. I., \& Hanson, D. R. (2005). Human development: Biological and genetic processes. Annual Review of Psychology(56), 263-286. doi:

10.1146/annurev.psych.56.091103.070208

Gould, D., Dieffenbach, K., \& Moffett, A. (2002). Psychological characteristics and their development in Olympic champions. Journal of Applied Sport Psychology, 14, 172204. doi: $10.1080 / 10413200290103482$

Gould, D., Hodge, K., Peterson, K., \& Petlichkoff, L. (1987). Psychological foundations of coaching: Similarities and differences among intercollegiate wrestling coaches. The Sport Pscyhologist, 1, 293-308.

Gucciardi, D. F., \& Gordon, S. (2009). Revisiting the performance profiling technique: Theoretical underpinnings and application. The Sport Psychologist, 23, 93-117. 
Running head: MENTAL TOUGHNESS IN ADOLESCENT PERFORMERS

Gucciardi, D. F., Gordon, S., \& Dimmock, J. (2008). Towards an understanding of mental toughness in Australian football. Journal of Applied Sport Psychology, 20, 261-281. doi: 10.1080/10413200801998556

Gucciardi, D. F., Gordon, S., \& Dimmock, J. (2009). Evaluation of a mental toughness training program for youth-aged Australian footballers: I. a quantitative analysis. Journal of Applied Sport Psychology, 21, 307-323.

Gucciardi, D. F., Gordon, S., Dimmock, J., \& Mallett, C. J. (2009). Understanding the coach's role in the development of mental toughness: Perspectives of elite Australian football coaches. Journal of Sport Sciences, 27, 1483-1496. doi: $10.1080 / 02640410903150475$

Gucciardi, D. F., Hanton, S., \& Mallett, C. J. (2012). Progressing measurement in mental toughness: A case example of the Mental Toughness Questionnaire-48. Sport, Exercise, and Performance Psychology, 1, 194-214. doi: 10.1037/a0027190

Hardy, L., Bell, J. J., \& Beattie, S. (2013). A neuropsychological model of mentally tough behavior. Journal of Personality. doi: 10.1111/jopy.12034

Hilbrecht, M., Zuzanek, J., \& Mannell, R. C. (2008). Time use, time pressure and gendered behavior in early and late adolescence. Sex Roles, 58, 342-357. doi: 10.1007/s11199007-9347-5

Horsburgh, V. A., Schermer, J. A., Veselka, L., \& Vernon, P. A. (2009). A behavioural genetic study of mental toughness and personality. Personality and Individual Differences, 46, 100-105.

Huurre, T., Eerola, M., Rahkonen, O., \& Aro, H. (2007). Does social support affect the relationship between socioeconomic status and depression? A longitudinal study from adolescence to adulthood. Journal of Affective Disorders, 100, 55-64. doi: 10.1016/j.jad.2006.09.019 
Running head: MENTAL TOUGHNESS IN ADOLESCENT PERFORMERS

Johnson, W., Hicks, B. M., McGue, M., \& Iaconno, W. G. (2007). Most of the girls are alright, but some aren't: Personality trajectory groups from age 14 to 24 and some associations with outcomes. Journal of Personality and Social Psychology, 93, 266284. doi: 10.1037/0022-3514.93.2.266

Jones, G., Hanton, S., \& Connaughton, D. (2002). What is this thing called mental toughness? An investigation of elite sport performers. Journal of Applied Sport Psychology, 14, 205-218. doi: 10.1080/10413200290103509

Jones, G., Hanton, S., \& Connaughton, D. (2007). A framework of mental toughness in the world's best performers. The Sport Psychologist, 21, 243-264.

Kashdan, T. B., \& Steger, M. F. (2007). Curiosity and pathways to well-being and meaning in life: Traits, states, and everyday behaviors. Motivation and Emotion, 31, 159-173. doi: http://dx.doi.org/10.1007/s11031-007-9068-7

Keating, D. P. (2004). Cognitive and brain development. In R. M. Lerner \& L. Steinberg (Eds.), Handbook of Adolescent Psychology (2nd ed., pp. 45-84). Hoboken, NJ: John Wiley \& Sons.

Krebs, R. J. (2009a). Bronfenbrenner's bioecological theory of human development and the process of development of sports talent. International Journal of Sport Psychology, $40,108-135$.

Krebs, R. J. (2009b). Proximal processes as the primary engines of development. International Journal of Sport Psychology, 40, 219-227.

Lazarus, R. S. (2000). How emotions influence performance in competitive sports. The Sport Psychologist, 14, 229-252.

Lincoln, Y. S., \& Guba, E. G. (1985). Naturalistic Inquiry. Beverly Hills, CA: Sage Publications. 
Running head: MENTAL TOUGHNESS IN ADOLESCENT PERFORMERS

Mallett, C. J., \& Coulter, T. J. (2011). Understanding and developing the will to win: Perceptions of parents, coaches, and players. In D. F. Gucciardi \& S. Gordon (Eds.), Mental toughness in sport: Developments in research and theory. London: Routledge.

Maslow, A. (1943). A theory of human motivation. Psychological Review, 50, 370-396. doi: $10.1037 / \mathrm{h} 0054346$

McLeod, J. (2009). Psychology and the Journal of Sport Sciences: Getting published. Journal of Sport Sciences, iFirst, 1-3.

Montemayor, R., Adams, G. R., \& Gullotta, T. P. (Eds.). (1990). From childhood to adolescence: A transitional period. Newbury Park, CA: Sage.

Patton, M. Q. (2002). Qualitative research and evaluation methods (3rd ed.). Thousand Oaks, CA: Sage.

Ryff, C. D., Singer, B., Love, G. D., \& Essex, M. J. (1998). Resilience in adulthood and later life. In J. Lomranz (Ed.), Handbook of aging and mental health: An integrative approach (pp. 69-96). New York: Plenum Press.

Schaal, K., Tafflet, M., Nassif, H., Thibault, V., Pichard, C., Alcotte, M., . . Toussaint, J. (2011). Psychological balance in high level athletes: Gender-based differences and sport-specific patterns. PLoS ONE, 6(5), e19007.

Storey, L. (2007). Doing interpretative phenomenological analysis. In E. Lyons \& A. Coyle (Eds.), Analysing qualitative data in psychology (pp. 51-64). London: Sage.

Susman, E. J., \& Rogol, A. (2004). Puberty and psychological development. In R. M. Lerner \& L. Steinberg (Eds.), Handbook of Adolescent Psychology (2nd ed., pp. 15-44). Hoboken, NJ: John Wiley \& Sons.

Thelwell, R. C., Such, B. A., Weston, N. J. V., Such, J. D., \& Greenlees, I. A. (2010). Developing mental toughness: Perceptions of elite female gymnasts. International 
Running head: MENTAL TOUGHNESS IN ADOLESCENT PERFORMERS

Journal of Sport and Exercise Psychology, 8, 170-188. doi:

10.1080/1612197X.2010.9671941

Vaughn, S., Schumm, J. S., \& Sinagub, J. (1996). Focus group interviews in education and psychology. Thousand Oaks, CA: Sage.

Weinberg, R., Butt, J., \& Culp, B. (2011). Coaches' views of mental toughness and how it is built. International Journal of Sport and Exercise Psychology, 9, 156-172. doi: 10.1080/1612197X.2011.567106

Yardley, L., \& Bishop, F. (2007). Mixing qualitative and quantitative methods: a pragmatic approach. In C. Willig \& W. Stainton-Rogers (Eds.), Handbook of Qualitative Research Methods in Psychology (pp. 352-369). London: Sage. 


\section{Running head: MENTAL TOUGHNESS IN ADOLESCENT PERFORMERS}

Table 1.

Personal Characteristics that Comprise Mental Toughness with Corresponding Contrasting Poles, Descriptions, Representative Quotes, and Frequencies per Performance Context.

\begin{tabular}{|c|c|c|c|c|}
\hline & Emergent pole (frequency) & Representative quote & Opposite pole & Representative quote \\
\hline \multirow[t]{4}{*}{$\begin{array}{l}\text { Personal } \\
\text { Forces }\end{array}$} & $\begin{array}{l}\text { Persistence: The ability to be effortful on } \\
\text { tasks even and especially when faced } \\
\text { with obstacles. } \\
(\mathrm{S}=5 ; \mathrm{A}=5 ; \mathrm{M}=3)\end{array}$ & $\begin{array}{l}\text { I'm motivated to achieve goals } \\
\text { even if the situation isn't ideal. }\end{array}$ & $\begin{array}{l}\text { Lazy: A tendency to give up, leave } \\
\text { tasks unfinished, or complete } \\
\text { the bare minimum. }\end{array}$ & $\begin{array}{l}\text { If tasks are too difficult or time } \\
\text { consuming they are not } \\
\text { complete. }\end{array}$ \\
\hline & $\begin{array}{l}\text { Drive: A strong appreciation for and/or } \\
\text { desire to engage in familiar as well as } \\
\text { novel tasks (often motivated by passion } \\
\text { or enjoyment). } \\
(\mathrm{S}=4 ; \mathrm{A}=3 ; \mathrm{M}=3)\end{array}$ & $\begin{array}{l}\text { I like learning about the topic and } \\
\text { enjoy working on it. }\end{array}$ & $\begin{array}{l}\text { Unmotivated: A wanning } \\
\text { enthusiasm to participate in } \\
\text { familiar and novel tasks. }\end{array}$ & $\begin{array}{l}\text { They aren't interested in the task } \\
\text { or, otherwise, feign interest } \\
\text { in it. }\end{array}$ \\
\hline & $\begin{array}{l}\text { High self-expectation: A desire to achieve } \\
\text { one's potential. } \\
\qquad(\mathrm{S}=5 ; \mathrm{A}=5 ; \mathrm{M}=4)\end{array}$ & $\begin{array}{l}\text { I'm always trying to make my } \\
\text { work or my form better. }\end{array}$ & $\begin{array}{c}\text { Compromising: A tendency to be } \\
\text { satisfied with mediocrity. }\end{array}$ & $\begin{array}{l}\text { When people can't be bothered to } \\
\text { try their best. }\end{array}$ \\
\hline & $\begin{array}{l}\text { Support seeking: A willingness to ask for } \\
\text { and accept the help of others. } \\
(\mathrm{S}=2 ; \mathrm{A}=3 ; \mathrm{M}=1)\end{array}$ & $\begin{array}{l}\text { I ask questions constantly to gain } \\
\text { the information I need to achieve } \\
\text { good outcomes. }\end{array}$ & $\begin{array}{l}\text { Support avoider: An arrogance } \\
\text { and/or fear of seeking the } \\
\text { support of others. }\end{array}$ & $\begin{array}{l}\text { They are too proud or too shy to } \\
\text { ask for assistance. }\end{array}$ \\
\hline $\begin{array}{l}\text { Personal } \\
\text { Resources }\end{array}$ & $\begin{array}{l}\text { Forethought: The ability to set, balance, and } \\
\text { commit to competing life demands. } \\
\qquad(\mathrm{S}=1 ; \mathrm{A}=3 ; \mathrm{M}=3)\end{array}$ & $\begin{array}{l}\text { I plan specific times to complete } \\
\text { tasks and also consider rest times } \\
\text { and extra curricular activities. }\end{array}$ & $\begin{array}{l}\text { Unorganised: An inability to } \\
\text { manage more than one tasks } \\
\text { at a time or balance multiple } \\
\text { tasks }\end{array}$ & $\begin{array}{l}\text { They complete tasks at random and } \\
\text { don't consider other } \\
\text { commitments. }\end{array}$ \\
\hline
\end{tabular}


Running head: MENTAL TOUGHNESS IN ADOLESCENT PERFORMERS

Social intelligence: An awareness of and ability to engage with others using prosocial behaviors to facilitate goal achievement.

$(\mathrm{S}=5 ; \mathrm{A}=3 ; \mathrm{M}=5)$

Heightened-awareness: The ability to use a knowledge of one's self, immediate surroundings, and in-the-moment experiences to being about goal achievement. $(\mathrm{S}=2 ; \mathrm{A}=4 ; \mathrm{M}=1)$

Self-belief: A belief in one's abilities to bring about goal achievement.

$(\mathrm{S}=2 ; \mathrm{A}=2 ; \mathrm{M}=1)$

Optimistic thinking: The tendency to expect positive outcomes in the future.

$(\mathrm{S}=2 ; \mathrm{A}=2 ; \mathrm{M}=4)$
I can easily work with others to

achieve positive outcomes. what is happening around me.

I believe I can achieve my goals. don't get caught up in the negative aspects.
Inconsiderate: A cold, disrespectful, and/or selfish disposition towards others.

Ignorant: Take experiences for granted and fails to contemplate what is occurring in and around them.

Self-doubt or arrogant: Either having too little or too much confidence.

Pessimistic thinking: A tendency to expect negative outcomes in the future.
They can't work with others or be trusted to complete things.

They are disinclined to question current pr provided methods.

Never being sure of what to do; an overconfidence.

Have a negative outlook on life.

Note. $\mathrm{S}=$ Sport; $\mathrm{A}=$ Academia; $\mathrm{M}=$ Music; numbers in parentheses indicates how many participants, by context, reported each emergent and opposing personal resource. 
Running head: MENTAL TOUGHNESS IN ADOLESCENT PERFORMERS

Table 2 .

The Higher and Lower Order Themes and Representative Quotes Pertaining to the Development of the Emerging Personal Attributes.

\begin{tabular}{|c|c|c|}
\hline Higher order theme & Lower order theme (frequency cited) & Representative quote \\
\hline Significant others & $\begin{array}{l}\text { Supportive social agents viewed as having a } \\
\text { direct and significant influence during } \\
\text { occasions related to performance. }\end{array}$ & $\begin{array}{l}\text { Dad ... Mom ... Brother } \ldots \text { Sister ... Teacher ... Coach ... Friends ... } \\
\qquad(S=6 ; A=6 ; M=6)\end{array}$ \\
\hline $\begin{array}{l}\text { Supportive social processes: } \\
\text { Activities within one's social } \\
\text { environment that advances the }\end{array}$ & $\begin{array}{l}\text { Autonomy: The provision of choice for } \\
\text { individuals to self-direct actions. }\end{array}$ & $\begin{array}{l}\text { Dad's a cyclist, but was never pushy, which I liked because I got to develop how I } \\
\text { wanted to develop. } \\
\qquad(\mathrm{S}=2 ; \mathrm{A}=1 ; \mathrm{M}=3)\end{array}$ \\
\hline \multirow[t]{3}{*}{$\begin{array}{l}\text { learning, understandings, and } \\
\text { abilities of an individual. }\end{array}$} & $\begin{array}{l}\text { Encouragement: The provision of positive verbal } \\
\text { support. }\end{array}$ & $\begin{array}{l}\text { For me there was that close group of [friends] who would help me out much like } \\
\text { my parents would. They would affirm me. } \\
\quad(S=6 ; A=6 ; M=6)\end{array}$ \\
\hline & $\begin{array}{l}\text { Challenge: The provision of scenarios where } \\
\text { individuals are pushed to the limits of their } \\
\text { abilities. }\end{array}$ & $\begin{array}{l}\text { The first commandment of an instructor should be to constantly have others out of } \\
\text { their comfort zone because in that environment that is where people develop } \\
\text { skills whether they believe they can or not. When [instructors] pushed me out } \\
\text { of my comfort zone it fed the fire that made me want to keep developing and } \\
\text { keep on going. } \\
(\mathrm{S}=5 ; \mathrm{A}=4 ; \mathrm{M}=5)\end{array}$ \\
\hline & $\begin{array}{l}\text { Role modeling: The demonstration of adaptive } \\
\text { behaviors that result in performance gains. }\end{array}$ & $\begin{array}{l}\text { My family is pretty musical and that made me determined to be as good as them. } \\
\text { They gave me a lot of self-belief because they had done so well. } \\
(\mathrm{S}=5 ; \mathrm{A}=4 ; \mathrm{M}=4)\end{array}$ \\
\hline $\begin{array}{l}\text { Critical incidents: Encounters } \\
\text { with experiences that offer }\end{array}$ & $\begin{array}{l}\text { Early successes: Positive outcomes experienced } \\
\text { during initial encounters with a performance }\end{array}$ & $\begin{array}{l}\text { I think starting at a young age is really beneficial because you pick up things } \\
\text { quickly and easily, so when you're older, and trying to learn an instrument and }\end{array}$ \\
\hline
\end{tabular}




\section{Running head: MENTAL TOUGHNESS IN ADOLESCENT PERFORMERS}

meaningful opportunities to

receive feedback about one's

abilities.

Curiosity: An interest in one's

world and experiences without

judgement. context.

Varied experiences: Exposure to a number of

different environments requiring a number of

different abilities.

Failures/setbacks: Exposure to experiences that

demonstrate inability on a performance task. you can't pick it up, you might get put off really easily.

$$
(\mathrm{S}=4 ; \mathrm{A}=5 ; \mathrm{M}=5)
$$

If you start really young, particularly in sport, you can get pushed really hard because you're achieving so well. When you get older that passion goes away because you're doing it so much.

$$
(\mathrm{S}=2 ; \mathrm{A}=1 ; \mathrm{M}=2)
$$

I think the failures that I have motivate me more than the success I might have. I'd rather work off something I did wrong last week and thinking how I'm going to do it better next week.

$$
(\mathrm{S}=6 ; \mathrm{A}=4 ; \mathrm{M}=5)
$$

I guess I'm a very curious person, which is why I pick up a lot of things from the environment that I'm in.

$(\mathrm{S}=3 ; \mathrm{A}=4 ; \mathrm{M}=3)$

Note. $\mathrm{S}=$ Sport; $\mathrm{A}=$ Academia; $\mathrm{M}=$ Music; numbers in parentheses indicates how many participants, by context, reported each developmental factor. 